\title{
Mobile Applications and Discrete Event Systems: \\ Low Cost Technology to Assist Stock Management in an Orthopaedic Clinic
}

\author{
Daniela Trindade Batista ${ }^{1}$, Thiago Augusto Santos Ferreira ${ }^{1}$, Renata Duarte Mellim ${ }^{1}$, \\ Luiz Melk de Carvalho ${ }^{1}$, Flávio Henrique Batista de Souza ${ }^{1}$, Vladimir Alexei Rodrigues \\ Rocha $^{2}$ \\ ${ }^{1}$ Centro Universitário de Belo Horizonte UNIBH, Brazil \\ ${ }^{2}$ Universidade Federal de Minas Gerais, Brazil \\ *Corresponding author: flabasouza@yahoo.com.br
}

\begin{abstract}
.
This paper presents a case study of an inventory management in a medical orthopedic clinic in Belo Horizonte, a 3,000,000 inhabitant's city from Brazil. The main objective is to help on the management of supplies to avoid a lack and/or an excess of resources, to eliminate additional costs to the company. The proposed method was based on three steps: firstly, an organizational study of the materials and people involved in the inventory process was made, based on the statistical analysis of material inputs and outputs; secondly, the requirements analysis was executed for the development of a mobile application, responsible for the consolidation and standardization of inventory data; then, a system based on Stochastic Petri Nets (SPN) was developed to simulate scenarios of material availability. As result, the statistical analysis of the scenario of a set of materials commonly used found a lack of inventory data standardization, which justifies the demand for an easy and accessible management tools. Thus, a mobile application for data collection and standardization was developed. The data consolidation is performed through cloud computing, in .csv format, making analysis available in software such as $\mathrm{R} \circledast$, Matlab® and Excel®. Such dataset was used as the reference for SPN transitions firing process. Through SPN it was simulated scenarios for material availability prediction. Several experiments were performed and they predicted the excess and lack of materials such as Xylocaine, Neocain and compresses. Savings of thousands of Brazilian reais were recorded, as well as prevention of stockouts.
\end{abstract}

Keywords: Health care; Mobile Application; Orthopedic Clinic; Stochastic Petri Nets; Stock Management. 


\section{Introduction}

Inventory management can be crucial to ensure good business management, as a way to have the required product available when needed, and to focus on cost reduction. Through the technological concepts of organizational tools, it is possible to optimize with simple and lowcost methods the inventory management process of a small clinic specialized in orthopedics and traumatology in Belo Horizonte, a city of 3,000,000 inhabitants. In a scenario with many obstacles for small and micro entrepreneurs, simple, replicable, efficient, effective and lowcost solutions are highlighted.

These solutions may be based on mobile technologies, associated with the use of cloud computing and may offer standardization and access availability (Tan, 2019). The format of the collected data should conform to a standard that is as adaptable as possible, such as csv (comma-separated-values). With this prerogative, it is possible that literature tools can enable extensions of the capabilities of the systems used, such as the possibility of scenario simulations.

Focusing on the possibility of scenario simulation (for the economics of inputs, which can be extremely important for a small enterprise), another tool that was used in this research, the Petri nets (PN). They are a structure widely used in the literature and free of charge, which have been used in various situations, such as curd production (Reis et al., 2018) and pharmaceuticals inventory control (Souza et al, 2019). A specific type of PN, Stochastic Petri Nets (SPN) enable simulations according to a stochastic resource availability behavior (Lisboa et al. 2019).

Thus, the general objective of this research is to demonstrate, through the use of mobile solutions and discrete event simulation based on stochastic Petri nets (SPN), the optimization of the inventory management process of a company focused on the orthopedics sector. Characterizing as specific objectives: to present a diagnosis of the environment; generate an application that can assist and standardize inventory data collection; present a simulation framework that can not only abstract reality but also propose scenarios; and demonstrate a financial analysis of the entire process involved.

This work is justified by the demand for optimization and updating of the company in relation to its processes, in order to make what was previously done empirically, in a standardized way and with technologies being used with a pre-defined objective.

\section{Materials and Methods}

\subsection{App Inventor for Mobile Applications}

App Inventor is a functional tool that has a free version. This enables the design of mobile applications with Android platform (MIT App Inventor, 2019). The application development process in this software is made easy due to code blocks. This software has a simplified and fast language compared to other methods of creation.

\subsection{Stochastic Petri Nets}

The Petri net consists of a directed, split graph containing state nodes (places $P$ ) and event nodes (transitions $T$ - if this element is black, there is no timeout; if blank, a deterministic or stochastic timeout, must be waited for firing) where they are interconnected by means of 
oriented segments, the $\operatorname{arcs} A$, thus representing the flow between states and events. A state is represented by circles and can have one or more tokens (marks that represent the existence or otherwise of a resource) (Cassandras and Lafortune, 2008). The transitional nodes are represented by rectangles. A mark-up vector is an event of a simulation table, containing the simulation data. In the case of Figure 1, the marking vector $x$ contains the number of tokens in each place, in the case $x=\left[\begin{array}{ll}1 & 0\end{array}\right]$.

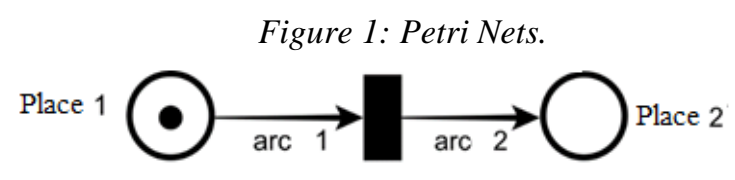

Source: authors, 2019

According to Lisboa et al (2019), a transition $T$ can fire obeying a time delay based in distribution function and is a tuple $\operatorname{SPN}=(P, T, A, w, x, \Lambda)$, where: $\Lambda=\left(\lambda_{1}, \lambda_{2}, \ldots, \lambda_{\mathrm{n}}\right)$ is added as an array of (possibly marking dependent) firing rates associated with transitions (associated to a exponential distribution).

\subsection{Research Method}

An environmental assessment was carried out through a technical visit, where the company operates in the orthopedics market and is in the city of Belo Horizonte (State of Minas Gerais / Brazil). A data collection process was carried out in the company object of the research, which was carried out for seven months, in loco by the authors, through documentary data extracted from the company processes. The appraised company provided data on the products it works with, in quantities and purchase and sale prices, over the seven-month period from September 2018 to March 2019.

Through the data provided it was possible to perform an analysis of how products enter and leave the stock, and thus develop the discrete event simulation. Also developed a flowchart, which shows the entire inventory process. Then, a mobile solution, via App Inventor, was developed to act on the inventory management process to optimize information gathering.

Thus, a simulation structure was implemented, using the Petri Nets tool, which can not only abstract reality, but also propose scenarios, in order to evaluate the effects of buying and selling in inventory. It was analyzed which types of drugs are idle in inventory, which are the ones with the highest turnover, which are the periods of stock of medicines and which lead times for delivery after purchase order. Based on the simulations, the needs are demonstrated as: hire, dismiss, readjust or train the employees analyzing the viability for the company.

\section{Results and Discussion}

\subsection{Process Flow Analyzed}

The purchase process is carried out through the purchase order which is sent in print to the administration department. This request is prepared by the nursing team, based on the stock analysis, where the quantity of each hospital material and medication is verified. Normally the request is made every two months. The purchase process flow is shown in Figure 2.

Figure 2: Purchase Flow 


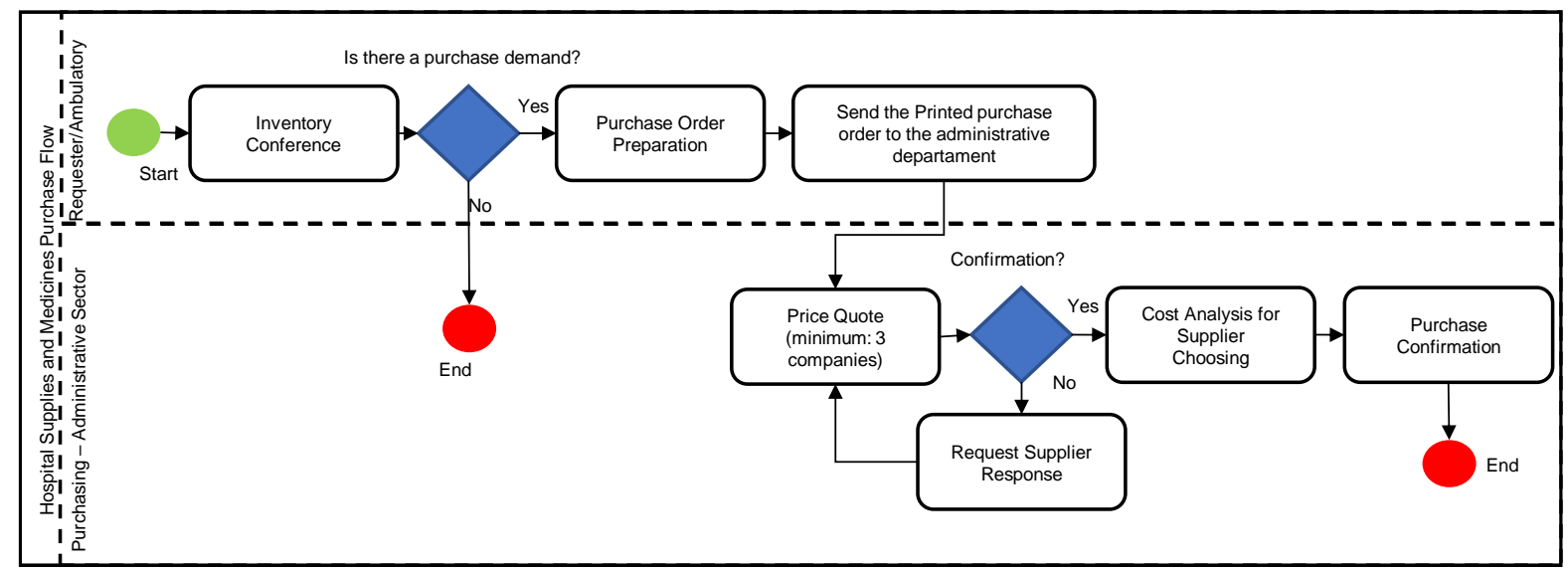

Source: (Authors, 2019)

After defining the quantity and which products will need to be purchased, quotes are made via email and telephone. The criterion of choice of the supplier is according to the cost benefit, deadline and delivery terms. Supplies and medicines usually arrive the same day or the day after the order. Thus, begins the flow of inventory control (Figure 3).

Figure 3: Inventory control

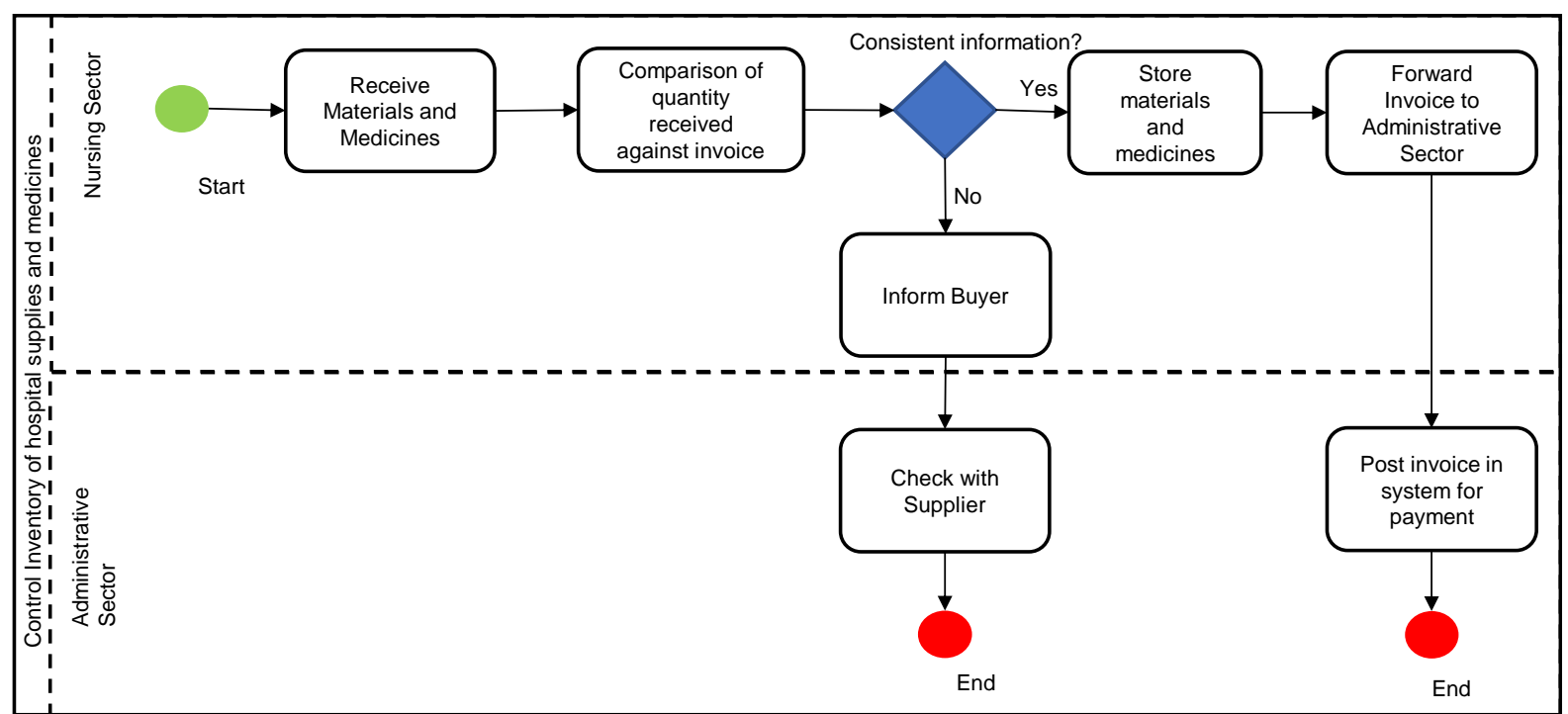

Source: (Authors, 2019)

Upon arrival, it is verified by the nurse who checks with the invoice if the quantity of products, the batch and the validity are correct. The conference is completed, materials and medicines are stored, and the invoice is sent to the administrative department, which posts the invoice into the payment management system.

\subsection{Mobile Application for Data Collection}

For the process of data collection and storage, an application was developed, with the aid of the MIT App Inventor tool, which through simple interfaces allows the user to record the incoming and outgoing hospital supplies and medicines from the stock, facilitating control, checking and increasing the reliability of information. In addition, the application provides 
10th International Conference on Research in

ENGINEERING, SCIENCE \& TECHNOLOGY

Rome, Italy

21-23 February 2020

relevant users with clarifications regarding the total stock value and movement history. Figure 4 shows the app diagram and Table 1 shows the screen palette.

Figure 4: Mobile Application Structure Diagram

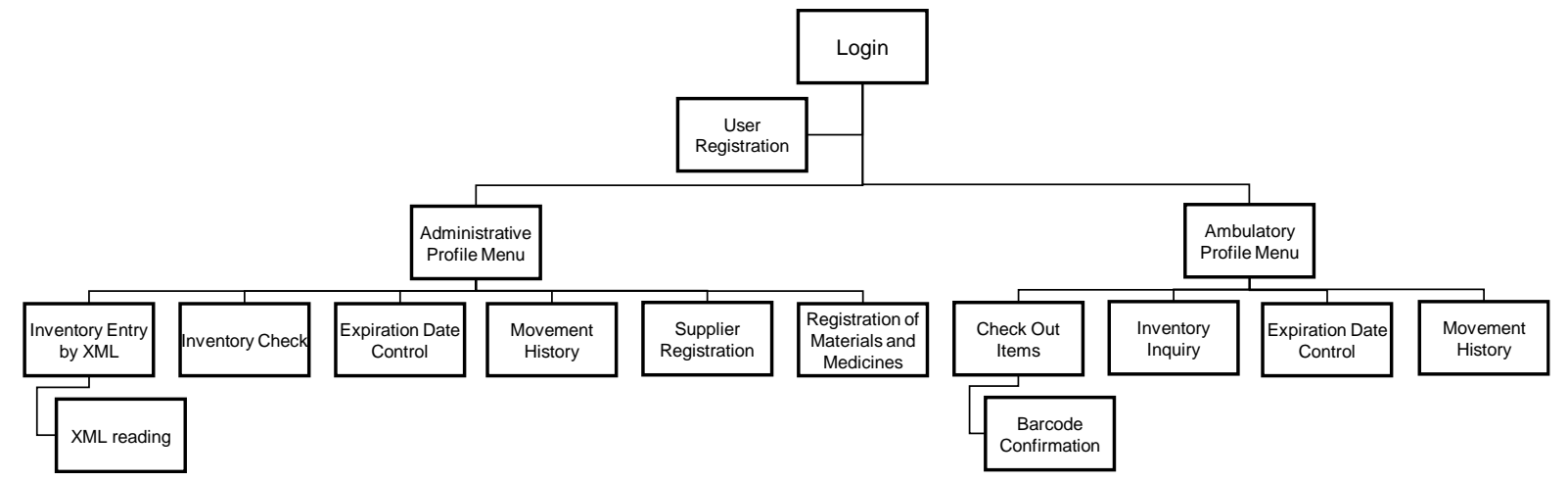

Source: (Authors, 2019)

Table 1: Mobile Application Screenshots

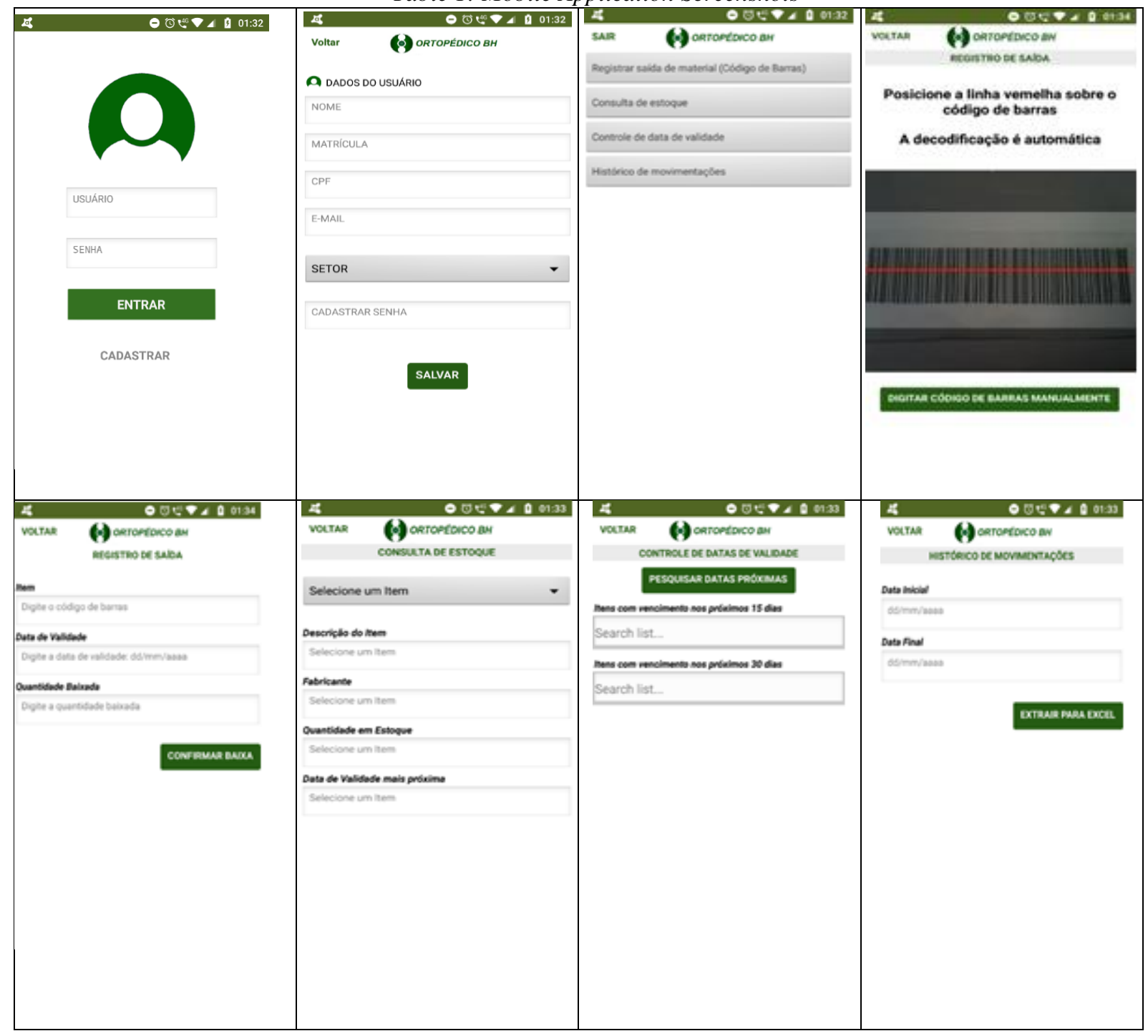




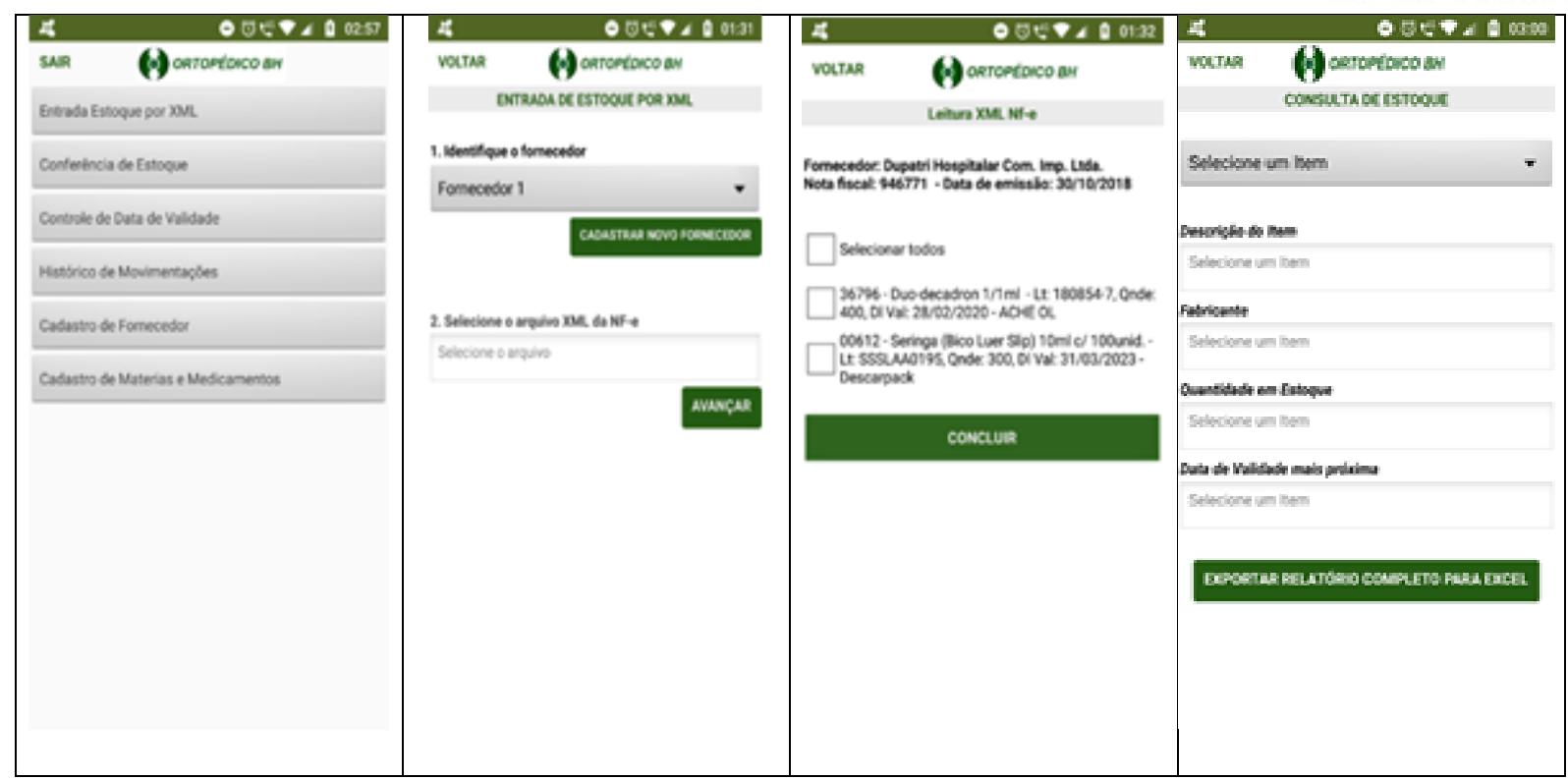

Source: (Authors, 2019)

The app has as an initial screen an interface that allows the user to login to the app through their registration in the company and a password previously registered. If the user does not have a registration, on the same screen the individual has the option of being able to register as a user, being directed to a new page, where they must fill in their data.

The user must register using their registration number registered with the company upon admission, as well as their full name, social security number (CPF), corporate email (if any) and select one of the two options related to the work sector: o administrative sector or the outpatient sector, which will define what type of access and what features the user will have available.

Once completed, the user must save this information and a message will appear at the bottom of the screen stating that registration will be completed after authorization and confirmation of a key user of the app. All entries will be directed to key users by email for verification and release of login.

Upon login, the user is directed to the menu page, according to their registered profile. The outpatient profile menu, which will be used by nurses, will have access to only the workrelated functionalities, intended for logging out and inventory control, which are:

1) Post Material Issue (Bar Code): This screen will carry out inventory issue records. To identify the product, it will be necessary to scan the barcode for automatic decoding through the camera of the mobile phone or tablet or you can enter the barcode manually, in case the package has only the numbers. After reading the barcode, the user will be directed to the item confirmation screen, where the product specifications will already be listed and just enter the quantity to be used;

2) Inventory Inquiry: The purpose of this research is to search for the availability of an item already registered in stock through a floating menu, reducing the need for access to physical inventory unnecessarily; 
3) Expiration date control: It is possible to make a general consultation of all upcoming hospital supplies and medicines. Clicking on the search for upcoming dates button will list all items due within the next 15 days and below, a list of all items due within the next 30 days to prevent the loss of items due. Expiration in stock;

4) Movement History: This functionality allows the user to export to an Excel spreadsheet all inventory movements in each period, generating a control and history of, for example, turnover of items that may influence some strategic decisions, such as material purchase order date.

The administrative profile menu will have access to some more features of the application in relation to the ambulatory profile, which are:

1) Inventory Entry by XML: This page will post the inventory entries. The administrative user will select the invoice XML file that was sent by the vendor and then will be directed to the XML file reading screen to confirm the entry of the products. The XML file contains the necessary information for the process such as quantity purchased, expiration date, and other tax data;

2) Inventory Checking: As described in the Outpatient Profile Inventory Inquiry function, this function will also allow the user to search for the availability of any item, but will also have the export functionality to Excel for the complete list of items in stock, together with their quantity and values and also the total value in stock;

3) Expiration date control: has the same functionality of the function in the outpatient profile;

4) History of movements: has the same functionality of the function in the outpatient profile;

5) Supplier registration: where the supplier registration is performed, necessary item due to the particulars in the invoice formats and also to ensure the traceability of products faster;

6) Registration of materials and medicines: where the registration of hospital materials and medicines is performed. The registration of suppliers, materials and medicines must be done before importing the XML file.

In short, the application works so that the administrative sector, responsible for purchasing material, makes the entries of items in the system and the outpatient sector, responsible for the

consumption of materials, makes the exits allowing the company to perform better inventory controls and being possible develop consumption scenarios that influence when and how much to buy.

The data from the application will be stored in the cloud, on the company's own intranet servers, thus preventing access outside the desktop, and will connect to the existing ERP by connecting to the existing processes. The databases will also be linked to a Petri Nets simulator in which it will be possible to have more accurate forecasts of material turnover as viewed in Appendix I.

\subsection{Simulator}

For the development of the simulation, the data were collected, even without due treatment (since the company was not properly rigorous with the data processing) and the statistical 
profiles (such as averages and distribution) for the development of the data were analyzed. SPN based simulator. The averages found were used for the shoot evaluations, by means of an exponential stochastic function.

\subsubsection{Scenario I Simulation}

The first scenario to be presented in this study selected eight items, which had the highest consumption and which were most relevant in terms of purchasing and use in procedures, to perform a first consumption / replenishment stock simulation according to the data collected in the period. six months of research.

After circumventing all the difficulties encountered in consolidating data and performing the appropriate abstractions, a simulator with the eight items was created, which can be viewed in Figure 5 (with two results exemplified in the graphs in Figure 6) to project the data. Current and verify their behavior.

To perform the simulations abstractions, the input and output data of the items were divided by a simple average in order to obtain the average movement times.

For example, 1380 units of a particular type of syringe were used. This value was divided by 6 (months) and again by 30 (days) reaching the approximate value of 8 units used per day.

Regarding purchases, the simple average of the different invoices was performed, and the purchase interval was obtained by dividing the quantity of purchases by the total days of the analyzed period. The behavior used to perform the simulation was an exponential distribution of time where the established time indicates the average trigger time, in the real case the average purchase time.

In this first scenario a 730 time limiter was used, which would be equivalent to 730 days, or 2 years. 
10th International Conference on Research in

ENGINEERING, SCIENCE \& TECHNOLOGY

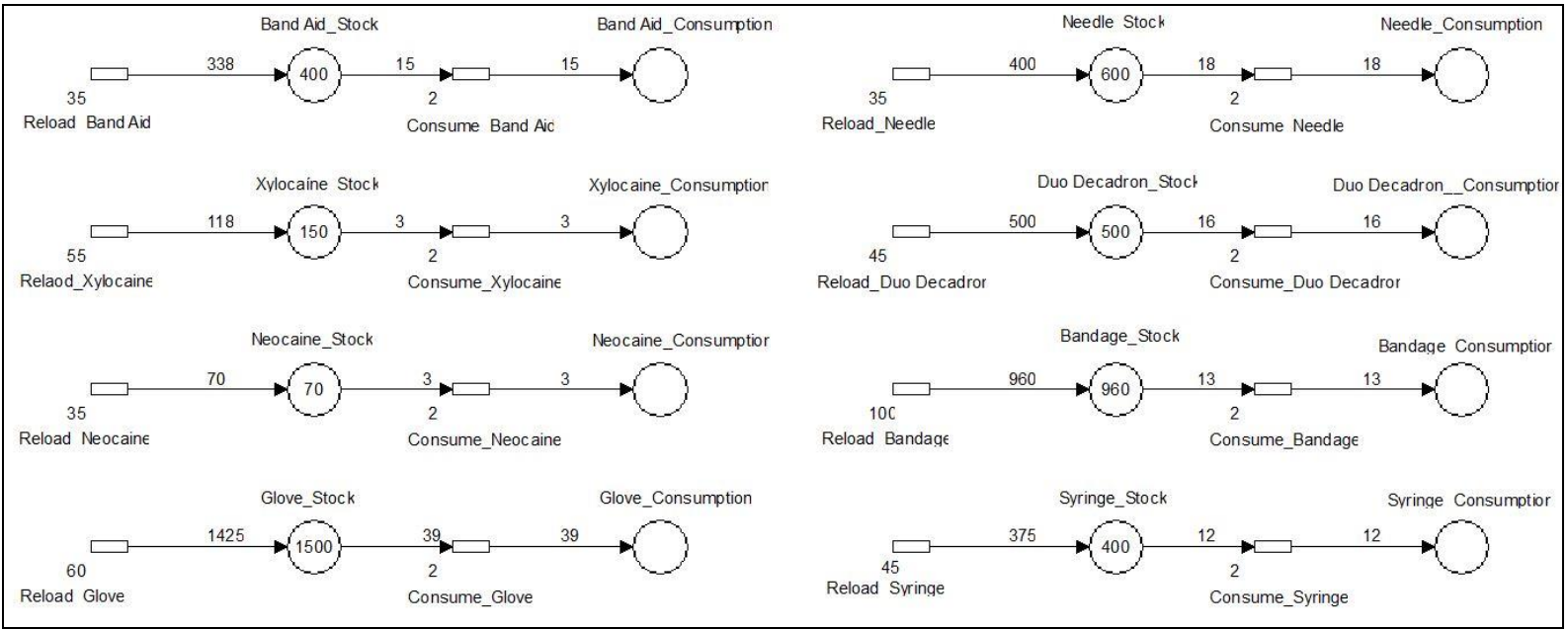

Source: (Authors, 2019)

Figure 6 - Stock Charts Example - Scenario I

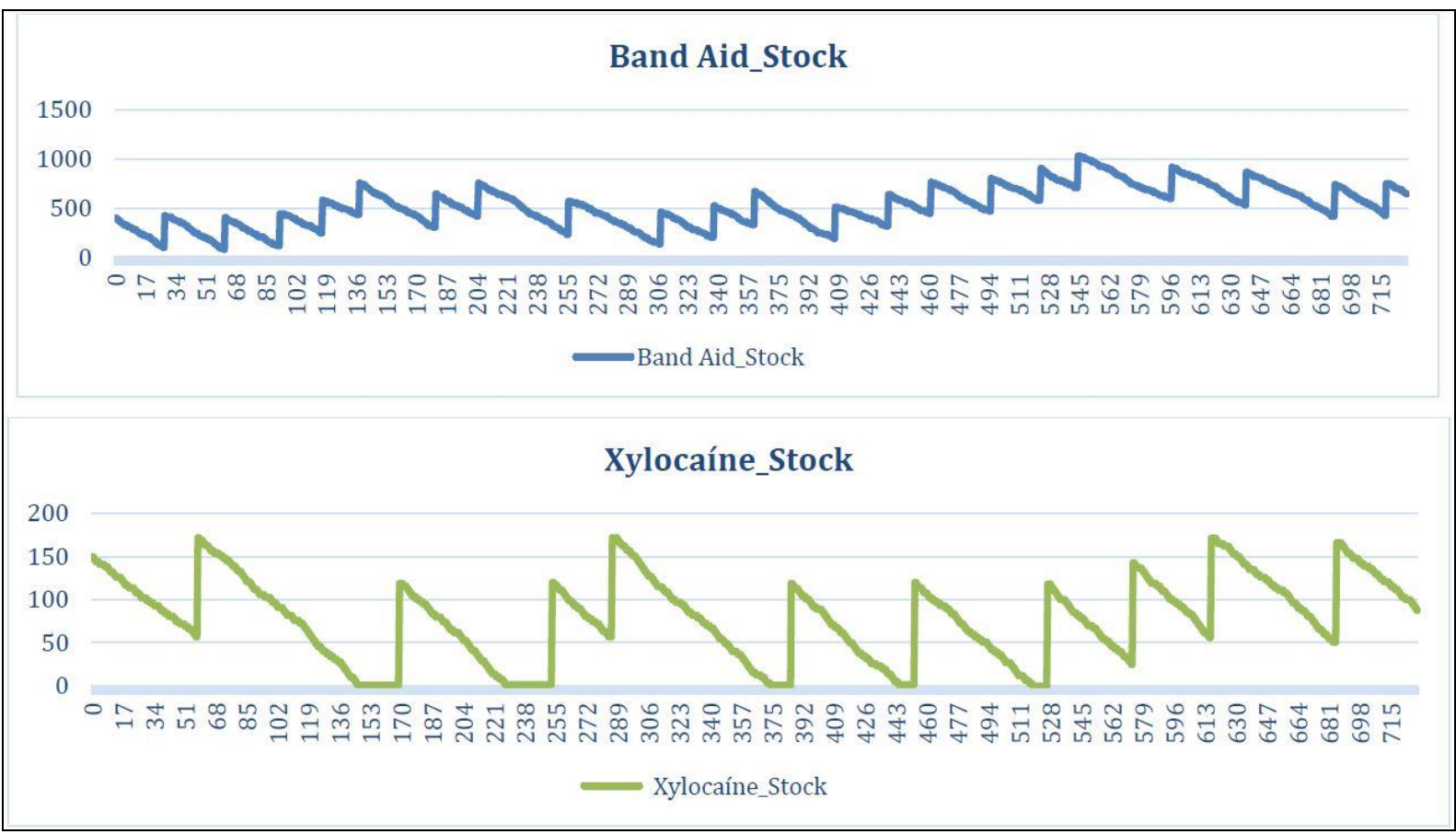

Source: (Authors, 2019)

The initial model returned the observed "sawtooth" graphs, common in the representation of stock fluctuations, relatively well represented the actual scenario observed in practice: purchases being made with stock still stocked resulting in unnecessary fixed capital for the moment due to no Correct alignment of items such as safety stock, consumption metering, and purchase decision related to the simple subjectivity of the item is ending or not.

It is noteworthy that by obtaining accurate real data to feed the model, the simulation will abstract reality with the considerable efficiency and precision needed to enable strategic analyzes guided by discrete event scenario simulations. 


\subsubsection{Scenario II Simulation}

The proposal for the elaboration was the reduction of the stock levels currently maintained to decrease the fixed capital for this purpose and freeing funds for other investments. In the proposed scenario, the purchase intervals were changed, as well as the quantities purchased, both undergoing reductions for the simulation, maintaining the time distribution method and the current consumption, as shown in Figure 7. The proposed simulation demonstrated the expected behavior, reducing safety stock levels as shown in the graphs in figure 8 .

Figure 7 - Petri net simulation - Scenario II

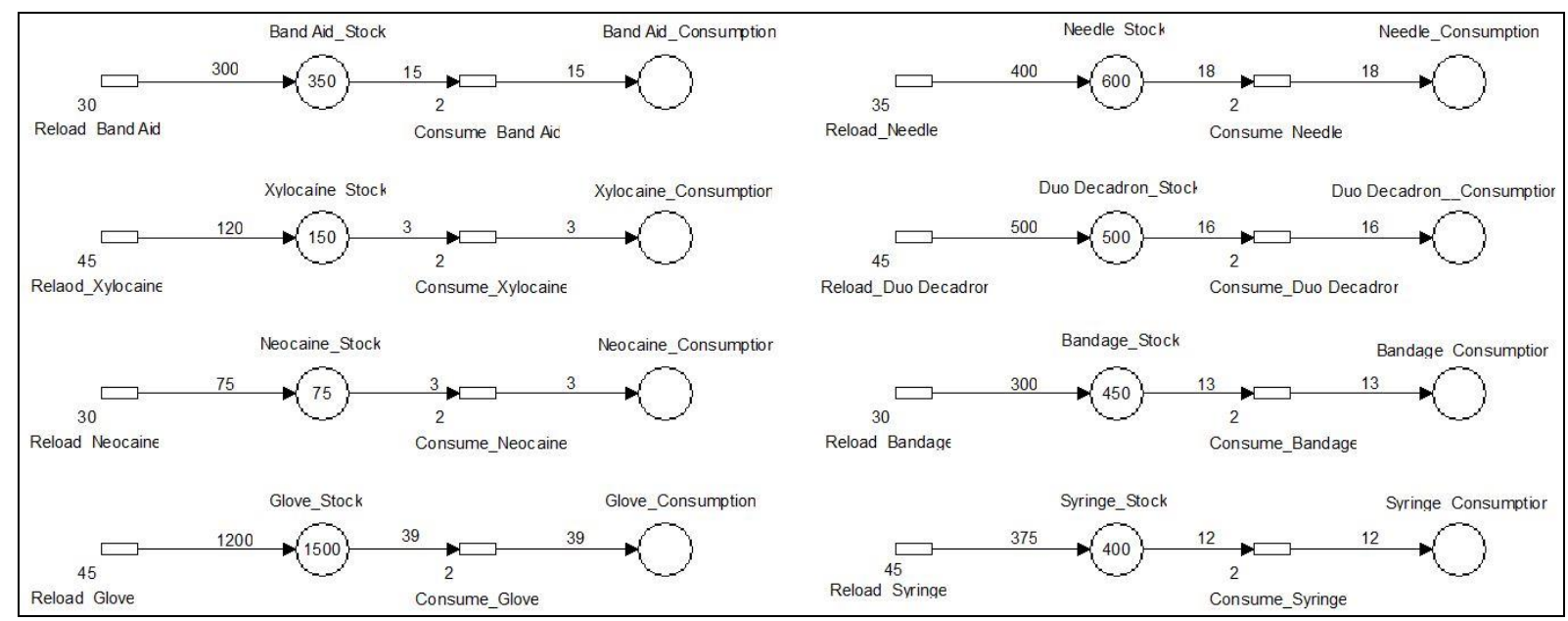

Source: (Authors, 2019) 


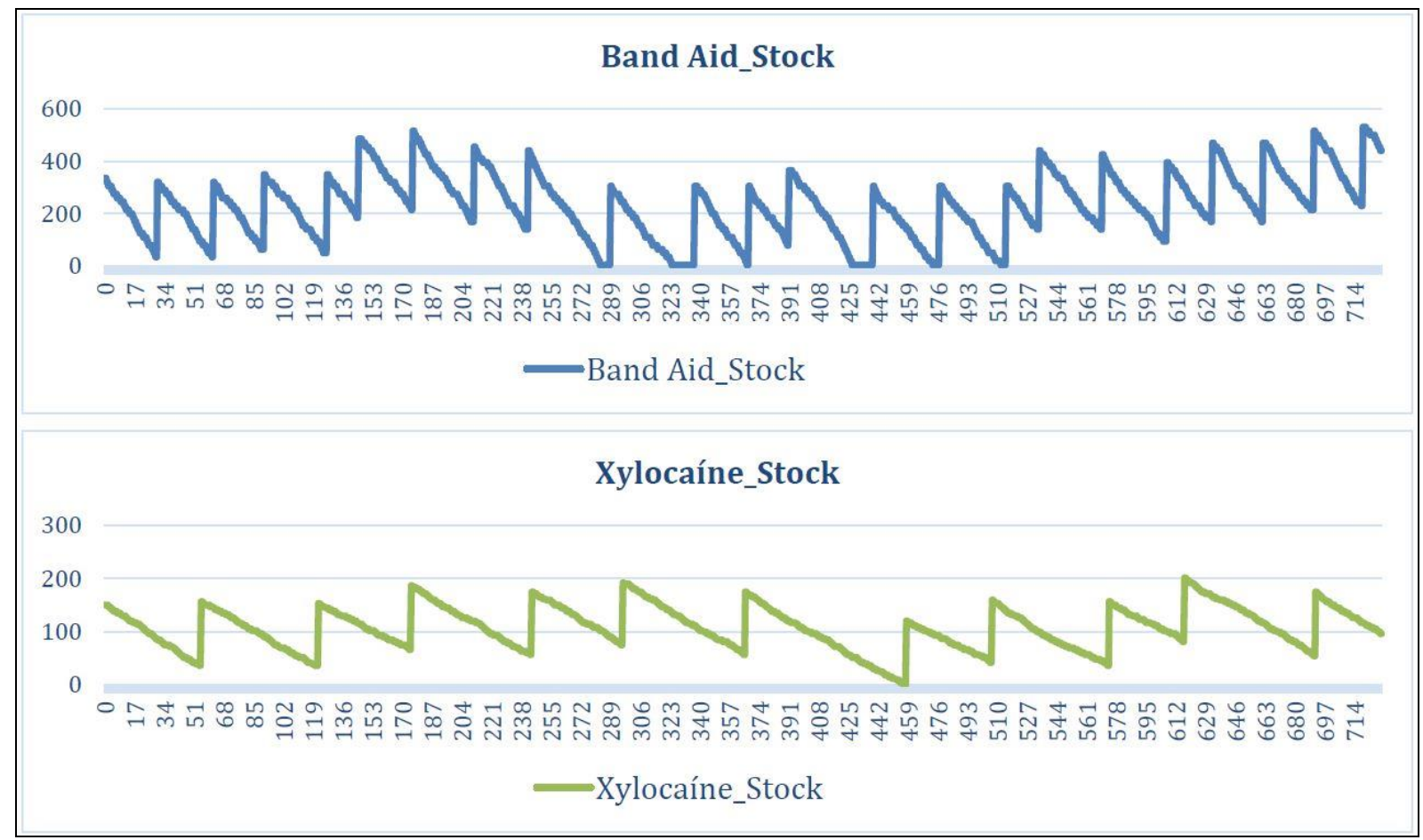

Source: (Authors, 2019)

\subsection{Financial Analysis}

For the implementation of the proposed new process, using the application as an ally to management, the cost for application development is estimated at around $\mathrm{R} \$ 20.000,00$ (considering that the analysis, interfaces and consolidation of the app data have already been raised and standardized in this article) and the purchase value of the mobile phone or tablet for each employee who will average $\mathrm{R} \$ 800,00$ each device.

As presented in the previous item, the performance over the two-year period was simulated, considering the actual data obtained from the average inventory inflows and outflows. In the results generated by the first simulation it was possible to observe the high average fixed assets of the listed items, which added up to $\mathrm{R} \$ 4.105,58$.

In the second scenario proposed in this study, the times between purchases were reduced and also some initial inventories were reduced, which led to a $33 \%$ reduction of the materials stopped in stock resulting in a sum added of $\mathrm{R} \$ 2.130,21$, a saving of $48 \%$.

The proposed purchase values are fictitious, but based on situations that may actually be executed. Maintaining inventories when properly performed allows fixed capital to be minimized, even while maintaining safety stocks, as it is not practicable for a medical clinic to work without inputs.

Assuming that the suggested simulation had the same impact on all other items in the current stock, it can be concluded that the alternative proposed in this article, of deploying an application that could control the stock while communicating with a Petri net to assess scenarios, you would have a payback within approximately 12 months. 


\section{Conclusion}

The inventory and purchase control process play an important strategic role in any company's business in order to ensure customer satisfaction. It was also found that the company did not use any method to manage its inventory.

This study aimed to optimize the current inventory management process of an orthopedic medical clinic by proposing a new data collection model and suggestions for improvements. During this work some limiting points were found, the main one being the lack of specific reports of inventory entries and exits, as well as the lack of consolidated inventory control, which caused difficulty in surveying the company's situation.

Based on the results found, it was found that it is possible to carry out inventory control without major problems and relatively simply, which would have as main benefit the direct financial return, generated by the correct management.

From this work it is suggested to implement the solutions, as well as the process monitoring indicators. Noting the feasibility of the project, after implementation, a comparison of previously fixed assets (without the use of tools) and an analysis of the stock after a certain method installation period would be performed, as well as the generated/saved values.

The impacts will be diagnosed through the constant use of the tool, compared to the old control method, visualizing the previous and current losses, optimizing the business management.

\section{References}

[1] CASSANDRAS, C. G.; LAFORTUNE, S. (2008) Introduction to Discrete Event Systems. 2. ed. - New York: Springer, 2008.

[2] TAN, J. (2019) Research on Smart Medical Cloud Application Service System Against the Backdrop of Smart City. Proceedings of International Conference on Management, Education Technology and Economics (ICMETE 2019). Atlantis Press.

[3] LISBOA, A. C., DE SOUZA, F. H., RIBEIRO, C. M., MAIA, C. A., SALDANHA, R. R., CASTRO, F. L. and VIEIRA, D. A. (2019). On modelling and simulating Open Pit mine through stochastic timed Petri nets. IEEE Access, 7, 112821-112835.

[4] MIT App Inventor (2019) Anyone Can Build Apps That Impact the World. Available in http://appinventor.mit.edu/explore/about-us.html .

[5] REIS, T., DARYANE, J. and SOUZA, F. H. B. D. (2018) Discrete Events Systems For Controlling The Production Process in a Dairy Industry. Proceedings of XXXVIII Encontro Nacional de Engenharia de Produção. Alagoas, Brazil. Available in: http://www.abepro.org.br/biblioteca/TN_STO_258_484_35879.pdf

[6] SOUZA, F. H. B. D., SILVA, N. N. and NOVAES, P. H. N. F. (2019) Ferramenta Baseada Em Eventos Discretos Para Gestão De Estoque Em Uma Pequena Empresa Do Ramo Farmacêutico. Proceedings of XXXIX Encontro Nacional de Engenharia de Produção. Santos, Brazil. Available http://www.abepro.org.br/biblioteca/TN_STO_292_1648_36823.pdf . 
10th International Conference on Research in

ENGINEERING, SCIENCE \& TECHNOLOGY

Rome, Italy

21-23 February 2020

Appendix I Mobile Solution Flowchart

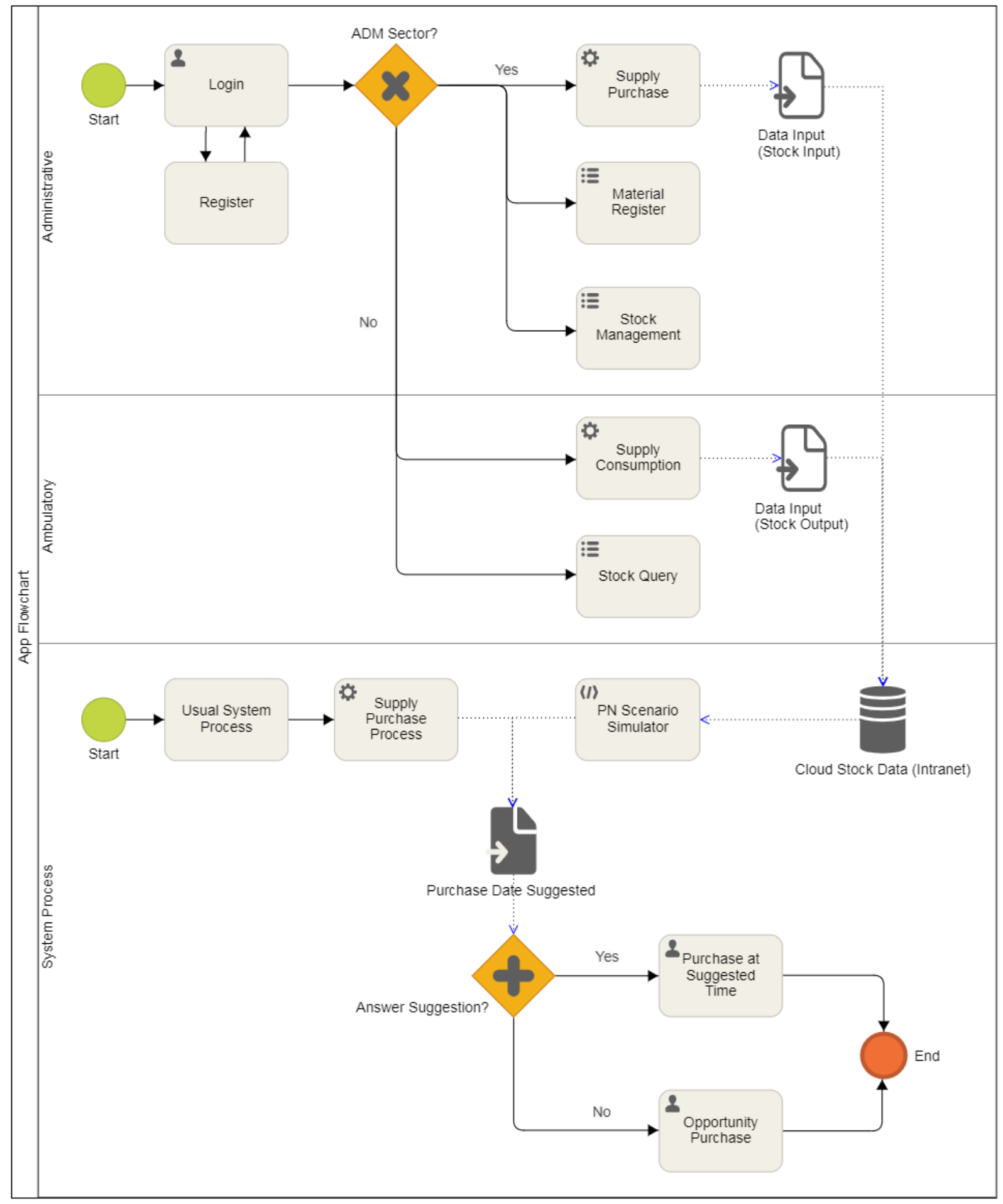

Source: (Authors, 2019) 